\title{
Healing Power of Awareness
}

\section{Willem A. Fonteijn}

GGZgroep, Amsterdam, The Netherlands

In psychotherapy, awareness is the major ingredient for sustainable and beneficial change. Clients are trained to become aware of their feelings and (hidden) thoughts. By doing so clients learn how to make better decisions and to cope with dysfunctional beliefs and emotions. For all of this awareness is the key ingredient.

The conditioned mind is not able to observe anything other than its own routine and habits. If a problem is raised the mind wants to solve it in a routine way. We need awareness to step out of the routine of the mind. By observing what is happening from moment to moment in a neutral way, we open up to new aspects of our environment and ourselves.

Awareness is the key ingredient in psychotherapy. For instance, psychoanalysis explores unconscious conflicts and brings them to awareness. CBT explores hidden dysfunctional key convictions and brings them to awareness to challenge them and transform them into functional beliefs. In the daily practice of psychotherapy, awareness is of ultimate importance. And still, we don't know so much about how to implicate awareness.

Let's illustrate the psychotherapeutic use of awareness with the case of John. John is just a normal guy, 40 years old with complaints about burnout. John is married; he has two daughters a nice house and some good friends. John is depressed, he has a low self-esteem, negative thoughts and John is suicidal. So far John did all kind of things to change his situation. He asked his friends for advice, went to fitness, analyzed his choices in life, blamed himself for making the wrong choices in his career, tried to escape from negative thoughts and failed in his efforts to create beneficial change. None of his efforts did succeed satisfactorily [1].

John comes to my office and seeks help. Why? John came to my office as many clients do when they seek psychotherapy. He wanted to end his suffering. As other clients do when they come to a psychotherapist, John seeks the end of suffering. The end of suffering from self-destructive convictions, bodily and mentally pain; suffering from dysfunctional emotions. In his endless self-talks, John searched in his mind for ways to end his suffering. The only answer he found in his mind was to add more control to what he was doing. More control over his behavior, more control over his emotions and more control over his thoughts. Since John sought for an answer in his mind', let's have a closer look at the nature of the mind. The mind is analyzing and clustering thoughts, emotions, and bodily sensations. The mind is evaluating the past and planning the future.

Part of our awareness is conditioned. That part structures its content depending on the conditions perceived. It perceives a sequence of incidents and structures a contingency. The conditioned part of our awareness is also known as mind. Mind is a very useful part of our awareness. It helps us, from moment to moment, to find our way through time and space.

We can ask ourselves how this conditioning actually happens? Do we condition ourselves to believe in the appearance of objects like tables and chairs? Do we order the objects to appear out of nothing? Of course not. This is really counterintuitive. The objects are just there

\section{Publication History:}

Received: November 09, 2018

Accepted: November 20, 2018

Published: November 22, 2018

\section{Keywords:}

Mindfulness, Depression, Quality of Life, Emotions, Anxiety, Awareness, Percutaneous Coronary Intervention, Self Concept

and will be there independent of our conditioned mind. The existence of the objects is not the result of conditioning. Objects are not provided by the mind. Only the appearance of the objects can be connected to the mind. And for the mind, this is all there is. Wherever we look we will not find any object as such. We can only be aware of its appearance. The mind doesn't explore objects as such. The mind explores thoughts, feelings and bodily sensations. The mind has conditioned itself, and by doing so; the mind can predict the occurrence of new events. It is our own awareness that is conditioned so that we can create expectations about a future moment and in that future moment compare the appearance of objects with our expectations.

The mind is categorizing experiences, coping with threat, seeking solutions for the individual. The mind is built as a complex of algorithms and by its nature bound by logic. The mind is very useful for solving problems, developing survival routines and developing cultural comfort. The mind is not useful for making an end to individual suffering. As the mind is not useful for making love. If we ask the mind to end suffering it will analyze suffering without finding a clue. It will start victimizing the individual. It will produce the same catastrophizing thoughts, experiencing the same feelings, making the same choices. And that was the case with John. He analyzed his suffering without finding a clue. He victimized himself, made the same bad choices, experienced the same depressed and desperate feelings, and came to the same conclusion: let's make an end to this. Conclusions, thoughts that elicited unpleasant feelings in the body which on their turn confirmed those conclusions.

What a smell is for the nose is a thought for thinking. As the body will react on a smell, so too, the body will react on a thought. The thinking mind creates stimuli for the body where the body will react on. All stimuli have this quality: pleasant, unpleasant and neutral. If the body perceives a pleasant stimulus, it will approach. If it perceives an unpleasant stimulus it will escape, and with a neutral stimulus the body will just go on with what it is doing. A body can escape from an unpleasant smell. Of course, a body can't from an unpleasant thought. The thought resides in the body and the body can't escape from itself. Freezing is the natural response of

"Corresponding Author: Dr. Willem A. Fonteijn, GGZgroep, Amsterdam, The Netherlands; E-mail: willemfonteijn@gmail.com

Citation: Fonteijn WA (2018) Healing Power of Awareness. Int J Clin Res Trials 3: 128. doi: https://doi.org/10.15344/2456-8007/2018/128

Copyright: (C) 2018 Fonteijn. This is an open-access article distributed under the terms of the Creative Commons Attribution License, which permits unrestricted use, distribution, and reproduction in any medium, provided the original author and source are credited. 
a body that can't escape from a thought. And while freezing occurs in the body, the mind gets absorbed by the negative thought. There seems to be no space anymore in the awareness around the thought.

Now let's shift to awareness. Awareness is what we want to explore in this paper and especially the healing power of awareness. As noted already, awareness is the key ingredient for change in psychotherapy. Another well-known author Eckart Tolle stated it like this: "Awareness is the greatest agent for change". What can we say about awareness? Awareness has this neutral observing quality. Awareness resides here and now, is being present with the stream of experiences. Awareness is open for new experiences, has a transforming quality. Awareness accepts an experience just as it is, without judgment. From the perspective of awareness, every experience is accepted as it is. Still, awareness is not a cold detached space. From my own experience, I know that awareness is concerned with experiences. You might say awareness is compassionate. For sure we know that awareness is Nomind; No-body; No-thing; No-one. Awareness is not an object. We know that we are aware as a subjective knowledge. Awareness resides at the very fundament of our existence. And still, awareness is easily overlooked. Awareness is like the Elephant in the room. One has to point to you the elephant before you can see it.

If we compare awareness and mind we come to the following remarks. The mind is conditioned, awareness is unconditioned. The mind minimizes threat and seeks comfort. The basic emotion of the mind is fear. The basic emotion of awareness is love.

\begin{tabular}{|l|l|}
\hline Mind & Awareness \\
\hline rigid & flexible \\
\hline closed & open \\
\hline anxiety and threat & love and opportunity \\
\hline survival mode & innovation mode \\
\hline conditioned & unconditioned \\
\hline controlling & observing \\
\hline doing & being \\
\hline criticizing & accepting \\
\hline Table 1: & \\
\hline
\end{tabular}

So how about the connection between the so-called me and awareness? One author Hamilton Boudreaux stated it like this: "Observe the space between your thoughts than observe the observer". I is not to be found in the mind. I is to be found in awareness. More likely I coincides with the observer. Another author, Rupert Spira, states it like this: "To believe that I, awareness, share the limits and the destiny of the mind and body is like believing that the screen shares the limits and destiny of a character in a movie". Where clients look for an answer to their suffering in the mind and identify themselves with the answers there to be found, we need to teach our clients to switch their perspective from mind to awareness. A switch in perspective that is to be demonstrated and trained in the here and now situation at the office of the psychotherapist. The therapist acts as a role model for the client. The therapist demonstrates an actual and compassionate containment of the emotions of the client and the psychotherapist. As a reference for here and now we use the body of the client. Carefully observe the body of the client and let the client likewise observe his or her body and become aware of the body. Learn the client that his or her body always reacts on stimuli like thoughts and sensations. That all those stimuli result in approach or escape behavior and if not so result in a freeze. Add awareness to the process. Learn the client to stay present. Observe the stimuli and the tendency to approach and escape. Allow change to happen. Use the body as a mirror for thoughts, focus on the bodily sensations and posture and notice the change in bodily sensations and posture. A change will happen all the time. To optimize this change in perspective we need to train attention. Attention brings phenomena to awareness. Attention is the gate to awareness. With mindfulness, we train attention, neutral attention. Neutral attention is like a light touch of attention to the object or experience to be observed. This in contrast to the absorbed attention. In the case of absorbed attention, awareness is narrowed. With neutral attention, awareness is broadened. There is a strong tendency to congruency in awareness. Bodily sensations, thoughts, and feelings mutually influence each other and are a cause for each other. You feel as you think and as you behave. For instance in the case of depression. Negative thoughts about the self and the world, a low mood and passive behavior. A body mind system in balance. No intrinsic urge for change. Unless the awareness of suffering. A state of suffering the individual wants to escape from but can't on its own.

For allowing change, beneficial change, to happen, and to facilitate the reoccurrence of beneficial change, we need a broad awareness. We need to cultivate neutral attention to create a broad awareness. The first step is to learn the client to focus on one neutral aspect in the body, for instance, the movement of the breath in the body. Or the touch of the feet with the ground [2]. Redirect the attention to this neutral aspect and notice how the awareness is broadened. Notice the change in bodily sensations and posture. Allow that change to happen. Stimulate curiosity. You can actively change the posture of the body and notice the effect of that change on mood and thoughts. Experiment with redirecting attention and broaden your awareness.

This method was used to treat John. So how is John now? His treatment lasted about 10 sessions during 6 months with practicing awareness in daily life in between the sessions. Crucial for John was to discover that he is not his thoughts. He learned to observe his thoughts just as they came and to facilitate new beneficial thoughts. He observed his mood and noticed the change in his mood and how this change become stronger and lasted through the day. After his treatment, John felt great. He was no longer suffering, accepting his life, more in connection and mindful. The key ingredients in Johns treatment were: noticing, naming and containing. Notice what comes to your awareness, recognize what it is and accept it. Containing instead of explaining.

Let's illustrate the process with the treatment of panic. We learn the patient to observe the occurrence of panic: There is panic, notice, and name panic. Attention wants to go away, wants to escape. The body can't escape, freezes. Panic is everywhere in the whole body. This must stop. I have to go away, to go outside...Bring your attention to the feet on the ground, feel your feet on the ground, just keep your attention there with your feet on the ground. what do you notice? .......panic vanishes.. and you calm down.

Practice your awareness in daily life and you will improve your quality of life. We offer this kind of treatment in a group or in individual sessions. It's the same procedure. For a further description, I refer my book: Circle of Awareness. We did some research with the use of this method for cardiac patients after receiving a PCI operation. A foursession group training was compared with self-help. We found that the group training resulted in a reduction of anxiety and depression and improved quality of life of the participants. 
In this study effects of a brief mindfulness-based stress reduction intervention were examined in cardiac patients who had a percutaneous coronary intervention (PCI). One-hundred-and-fourteen patients (mean age $55 \pm 7$ years, $18 \%$ women) were randomly assigned to a 4 -session mindfulness group intervention or a minimal mindfulness self-help control group that received a booklet containing identical information. Compared to self-help, the group intervention showed larger increases in psychological and social quality of life ( $\backslash \backslash .05$, partial g2 $=.04$ and .05 , respectively).

The case of Anna illustrates the healing power of awareness just in a short period of time.

Anna is a woman in her mid-forties. She joined a mindfulness retreat as part of her meditation practice. The circle was part of the program. Anna was excited by the method of the circle and kept on telling everyone how good the trainer had been on his job as well how nice it had been for her when she finally understood the process of insight meditation. Every time another participant stepped into the circle to explore his or her issues, Anna was eager to give her feedback about the psychological background of the issue raised. Finally, she stepped into the circle herself and wanted to explore her own feelings of inferiority. I started by suggesting to her how she might explore her feelings of inferiority by observing the way she moved her body.... Anna worked hard. She was able to express her thoughts and while doing so, explain them to the trainers. She replied that this was all very helpful in understanding her feelings of inferiority. Still, even though Anna stated that she understood it much better, her body showed no relief. She kept on walking with her head low and shoulders tense...... When I gave her this observation, she was surprised and confused. She tried to correct her posture and a painful expression came to her face. At the end of the group session that morning, while I gave some final remarks for the remainder of the program, Anna started to cry and said that it hurt very much. I asked her to stay while the rest of the group went for lunch, Sitting together I asked Anna to observe the pain and keep her focus on the pain by just observing the pain here and now. We both sat there for about half an hour and remained fully aware of the pain. Anna kept on saying how much it hurt and I supported her by inviting her to stay in the moment and allow the pain to be just as it is, In this state of full presence and awareness, a shift occurred. Anna became fully aware and clear minded. This state remained for the rest of the day and later Anna described this as real breakthrough and relief of her suffering from an abusive childhood.

\section{Competing Interests}

The author declare no competing interests.

\section{References}

1. Willem F (2016) Circle of Awareness. Using the body as a mirror for thoughts, Warden Press, Amsterdam.

2. Nyklicek I, Dijksman SC, Lenders PJ, Fonteijn WA, Koolen JJ, et al. (2014) A brief mindfulness based intervention for increase in emotional well-being and quality of life in percutanious coronary intervention (PCI) patients: The MindfulHeart randomized controlled trial. J Behav Med 37: 135-144. 